\title{
Association of Placental Tissue Estrogen Receptor Alpha Gene Expression with Postpartum Depression in Women at Risk: A Pilot Study
}

\author{
Richa Sharma ${ }^{1}$, Basu Dev Banerjee ${ }^{2}$, Manjeet Singh Bhatia ${ }^{3}$, Amita Suneja $^{4}$, Kiran Guleria $^{5}$, Neetu Chaudhary ${ }^{6}$
}

\begin{abstract}
Aim: A nested case-control study was conducted to establish an association of placental tissue estrogen receptor alpha gene expression with postpartum depression.

Materials and methods: Antenatal women were enrolled in their third trimester, and after delivery, their placentas of $1 \times 1 \mathrm{~cm}$ were stored in freezer at $-80^{\circ} \mathrm{C}$. Women were evaluated at 2 weeks and 6 weeks after delivery by Edinburgh Postnatal Depression Scale (EPDS) Hindi version, to identify postpartum depression (PPD) cases and controls.

Results: Out of 209 eligible women recruited, 30 PPD cases and 30 controls were identified on follow-up visits, and then, their stored placental tissues were analyzed for ESR $\alpha$ gene expression and the quantitative levels of ESR $\alpha$ RNA expression were evaluated. It was observed that ESR $\alpha$ gene was significantly downregulated by 1.33 times among cases as compared to controls, and the placental ESR $\alpha$ delta Ct value among cases was significantly higher with respect to controls.

Conclusion: Women developing PPD after delivery have significantly lower expression of ESR $\alpha$ gene in their placenta at the time of delivery, which is 1.33 times less as compared to women who remain healthy. The mean ESR $\alpha$ delta Ct value in PPD cases ( $3.33 \pm 0.697$ SD) was significantly higher than the controls $(2.91 \pm 0.759 \mathrm{SD})$, with $p$ value 0.032 . Thus, the downregulation of placental ESR $\alpha$ gene expression at delivery plays a crucial role in PPD.
\end{abstract}

Keywords: Antenatal Postpartum Depression Predictors Inventory-Revised, Estrogen receptor alpha gene, Postpartum depression. Journal of South Asian Federation of Obstetrics and Gynaecology (2020): 10.5005/jp-journals-10006-1842

\section{INTRODUCTION}

Postpartum period means period up to 6 weeks after delivery. Postpartum depression (PPD) is a serious condition that generally occurs at 4-6 weeks after delivery with features of low mood, sadness, low energy, forgetfulness, irritability, anxiety, mood swings, preoccupancy with infant well-being, anhedonia, sleep disturbance, decreased appetite, reduced libido, psychomotor disturbance, feeling of worthlessness, guilt, and suicidal ideation.

Postpartum depression according to International Classification of Disease 10 (ICD 10) is defined as the mental and behavioral disorder commencing within 6 weeks of delivery, which do not meet the criteria for disorder classified elsewhere. ${ }^{1}$ Many women experience self-limited and mild symptoms, but postpartum depression should be suspected when symptoms are severe and have lasted over 2 weeks. It usually begins between 2 weeks and a month after delivery. ${ }^{2}$ Recent studies have shown that $50 \%$ of postpartum depressive episodes actually begin prior to delivery. Therefore, in the Diagnostic and Statistical Manual of Mental Disorders 5th Edition (DSM V), postpartum depression is diagnosed under "depressive disorder with peripartum onset," in which peripartum onset is defined as anytime either during pregnancy or within the 4 weeks following delivery. PPD may last several months or even a year after delivery. ${ }^{3}$

The overall prevalence of PPD has been reported up to $60 \%$ depending on the population and study method. ${ }^{4}$ The prevalence of PPD in Indian population was found to be $15.8 \%$ attending postnatal clinic. ${ }^{5}$

Women are at higher risk of developing depression than men. After adolescence, incidence of depression in women is twice as
${ }^{1,4-6}$ Department of Obstetrics and Gynecology, University College of Medical Sciences and Guru Teg Bahadur Hospital, New Delhi, India

${ }^{2}$ Department of Biochemistry, University College of Medical Sciences and Guru Teg Bahadur Hospital, New Delhi, India

${ }^{3}$ Department of Psychiatry, University College of Medical Sciences and Guru Teg Bahadur Hospital, New Delhi, India

Corresponding Author: Richa Sharma, Department of Obstetrics and Gynecology, University College of Medical Sciences and Guru Teg Bahadur Hospital, New Delhi, India, Phone: +91 9868399747, e-mail: gautamdrricha1@gmail.com

How to cite this article: Sharma R, Banerjee BD, Bhatia MS, et al. Association of Placental Tissue Estrogen Receptor Alpha Gene Expression with Postpartum Depression in Women at Risk: A Pilot Study. J South Asian Feder Obst Gynae 2020;12(6):391-401.

Source of support: Nil

Conflict of interest: None

compared to men. While the relative risk of depression changes throughout the women's reproductive life cycle, the windows of increased vulnerability occur during periods of significant hormonal fluctuation $^{6}$ (i.e., puberty, postpartum period, and menopause).

Postpartum period is particularly important as depression at that time affects not only the women but also mother-child bonding, husband-wife relationship, interpersonal relations, and whole family. Depressed mothers may experience unnecessary suffering, deteriorating health status, marital discord, and suicidal 
ideation. Offspring of these depressed mothers have been shown to have significant emotional, cognitive, social, behavioral, and developmental delays, as well as an increased risk for mental disorders, which can persist throughout childhood. By considering all this, PPD has been called "the most significant obstetrical complication after delivery" and the illness was recently elevated to a "global health challenge" by the WHO.

PPD is a neglected condition in a developing country like India as it does not produce any gross symptoms, and hence, it is detected late or even may not be detected. Delay in delivering adequate treatment for PPD is unfortunate as the response to treatment is good, so effective detection becomes an important thing, which requires a good coordination of a wide variety of primary and secondary services including midwives, health visitors, clinical psychologists, and obstetricians.

As the preventive measures, early intervention and identification can alleviate suffering of the mother and minimize its potential harmful effects on the newborn. So, the first step in preventing PPD is the identification of women who are at risk for developing it. The risk factors that are strongly associated with PPD are as follows: low socioeconomic status, previous history of depression, antenatal depression or anxiety, marital dissatisfaction, low levels of social support, unemployment, job change, unwanted pregnancy, childcare stress, pressure for a male baby, and stressful events in life such as financial problem, serious illness, or death in family.

There is no single cause of PPD in women, but physical and emotional issues play a major role. Physical changes occurring after childbirth due to a dramatic drop in hormones (estrogen, progesterone, thyroid, serotonin levels) can contribute to PPD. Emotional factors include sleep deprivation, anxiety about newborn care and her physical appearance, struggle with sense of identity, or feel that she has lost control over her life; any of these issues can contribute to PPD.

Accumulative evidences ${ }^{2-5}$ suggest the role of estrogen in depression. Serotonin and noradrenaline are thought to play key roles in depression. Estrogen regulates serotonin receptor number and function controlling the activity of serotonergic neurons. Acute drop in the level of estrogen following expulsion of estrogensecreting placenta thus may cause sharp fall in serotonin levels leading to postpartum depression.

Estrogen exerts its biological effects in large part through intracellular activation of its principle receptors estrogen receptor alpha (ESR $\alpha)$ and estrogen receptor beta (ESR $\beta)$, but ESR $\alpha$ plays a more important role than ESR $\beta$ in emotions and mood..$^{10}$ Thus, the expression of ESR $\alpha$ gene can affect the whole pathway and lead to postpartum depression. ESR $\alpha$ has been documented in brain, reproductive organs (ovary, uterus, and cervix), and cytotrophoblast (CT) cells of the placenta. ${ }^{8}$

Many women suffering from postpartum depression fail to seek help due to social stigma and inadequate social support in a developing country like India. The purpose of our study is to determine the expression of placental ESR $\alpha$ in women with postpartum depression versus normal postpartum women in order to establish an association between placental ESR $\alpha$ and postpartum depression so that it can be taken as a predictor for PPD.

\section{Aim and Objectives}

\section{Aim}

To study the association of placental tissue estrogen receptor alpha gene expression with postpartum depression in women at risk.

\section{Primary Objective}

To compare the proportion of placental estrogen receptor alpha $(\mathrm{ESR} \alpha)$ gene expression in cases and controls.

\section{Secondary Objectives}

- to determine the proportion of postpartum depression

- to determine the correlation of placental tissue ESR $\alpha$ gene expression in each risk group listed in Antenatal Postpartum Depression Predictors Inventory-Revised (PDPI-R)

\section{Materials and Methods}

A nested case-control study was conducted in the Department of Obstetrics and Gynecology in collaboration with Molecular Biology Laboratory of Department of Biochemistry and Department of Psychiatry at our institution.

\section{Sample Size}

As there are no previous studies measuring the association between placental estrogen receptor alpha gene expression and postpartum depression, a sample size based on previous studies was not calculated. So as predecided to select 30 cases and 30 controls, we had to enroll 209 samples; out of them, 16 women were lost to follow-up and three women had EPDS scores 10,12, and 13, but they did not have depression on psychiatric evaluation, so were excluded from the study.

\section{Inclusion Criteria}

All pregnant women of any age, parity, and who were willing to participate in the study till the completion were enrolled for the study in third trimester if they had at least one of the following risk factors according to Antenatal Postpartum Depression Predictors Inventory-Revised (PDPI-R) ${ }^{12}$ :

- Single parent: divorced, widow, separated

- Low socioeconomic status (according to Modified Kuppuswamy Scale)

- Low self-esteem or negative self-estimation (does not feel good/ worthwhile/no good qualities)

- Past history of documented depression

- History of prenatal anxiety (feeling of uneasiness or apprehension concerning a vague nonspecific threat)

- Unplanned or unwanted pregnancy

- Lack of social support (both parents working, nuclear family, poor socioemotional support from paternal or maternal side, dependent on maid, etc.)

- Marital dissatisfaction (affection, communication, mutual activities)

- History of life stress

\section{Exclusion Criteria}

- Women with diagnosis of depression in current pregnancy

- Women with a history of psychiatric illness other than depression

\section{Selection of Controls}

- For each case, any age, religion, and residence were matched. Pregnant women in their third trimester matched with cases were recruited as controls

- Ethical clearance was obtained from institutional ethical clearance committee for human research. In third trimester, 
eligible antenatal women were enrolled for the study, and a detailed history with emphasis on sociodemographic status, obstetric history including planned or unplanned pregnancy, marital relationship, and previous history of depression was taken.

- Immediately after delivery of placenta, a piece of $1 \times 1 \mathrm{~cm}$ size of placenta was dissected out from maternal surface of the placenta, from periphery. Sample was collected in a sterile culture vial containing $5 \mathrm{~mL}$ phosphate-buffered saline (PBS) and initially stored in the freezer compartment of the labor ward fridge before transporting to the biochemistry. The samples were transferred to biochemistry department within 24 hours of collecting it, where they were stored in freezer at $-80^{\circ} \mathrm{C}$ for later estimation of ESR $\alpha$ gene expression.

Intrapartum and postpartum details along with the status of the child were also recorded. All enrolled women were followed at 2 weeks and 6 weeks after delivery for any symptom of postpartum depression. History of postpartum maternal morbidity or neonatal morbidity and mortality if any was documented at the time of visit. All women were assessed by Edinburgh Postnatal Depression Scale (EPDS) Hindi version. EPDS is a 10 -item, screening questionnaire for postpartum depression. It records the mental status of the mother, how she felt during the last seven days. Each item has four possible responses, which are scored from 0-3 depending on the severity of the responses. Higher scores indicate more severe depressive symptoms with a maximum total score of 30 . The recommended cutoff point is $9 / 10$. A score of 10 or higher may indicate that depression symptoms have been reported.

Scoring

- Q 1, 2 and 4 are scored 0, 1, 2 or 3 with top box scored as 0 and bottom box scored as 3 .

- Q 3,5-10 are reversed score with top box scored as 3 and the bottom box scored as 0 .

Maximum score: 30
Possible depression: 10 or greater

Always look at item "10" (suicidal thoughts)

- At 2-week follow-up, women were screened for PPD by this EPDS. Women scoring 10 or greater were taken to psychiatrist for evaluation and to confirm the postpartum depression as per ICD-10 criteria. Women who were confirmed with postpartum depression were selected as cases. Women with EPDS score less than 10 were followed up at 6 weeks and again screened at 6 weeks for PPD by EPDS. Women scoring 10 or greater were taken to psychiatrist for confirmation. After confirming, they were taken as cases. Equivalent number of women scoring less than 10 was selected as controls.

- At the end of the study, stored placental tissue of both cases and controls was analyzed for ESR $\alpha$ gene expression and the quantitative levels of ESR $\alpha$ RNA expression were evaluated by the following steps:

\section{o RNA Extraction}

RNA extraction was done using TRIzol reagent.

The tissue sample $(1 \times 1 \mathrm{~cm})$ was homogenized (using an automated homogenizer machine) (Fig. 1) in $1 \mathrm{~mL}$ TRIzol reagent at room temperature and cold centrifuged at $12,000 \mathrm{~g}$ for 10 minutes. The clear supernatant was transferred to a fresh tube, and $200 \mu \mathrm{L}$ of chloroform was added, followed by vigorous shaking of the tube for $10-15$ seconds. Then, the samples were centrifuged at $12,000 \mathrm{~g}$ for 15 minutes at $4^{\circ} \mathrm{C}$. The upper aqueous phase was collected into a fresh microcentrifuge tube, and $0.5 \mathrm{~mL}$ of isopropanol was added; the tube was incubated at room temperature for 10 minutes, followed by cold centrifuge at $12,000 \mathrm{~g}$ for 10 minutes. The supernatant was discarded, and the pellet was washed with $1 \mathrm{~mL} 75 \%$ ethanol and centrifuged at 7,500g for 5 minutes at $4^{\circ} \mathrm{C}$. The pellet was then air-dried for 5-10 minutes at room temperature and was resuspended in $30 \mu \mathrm{L}$ of RNase free water and stored at $-80^{\circ} \mathrm{C}$ until further use. The quantity

Subjects recruited to participate $(n=209)$

( Chosen according to the selection criteria and recruitment policy)

Lost to follow-up $=16$

Later excluded in the study $=3$

Participants with EPDS 10,12

and 13 but not found depressed

on psychiatric evaluation

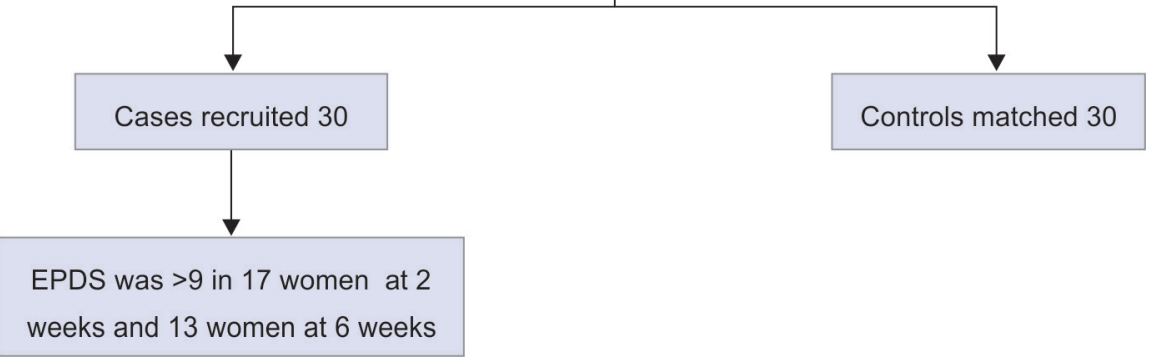

Fig. 1: CONSORT flow diagram 
of RNA was measured on nanodrop spectrophotometer (ND2000, Thermo Scientific USA).

o cDNA synthesis

$\square$ From the total RNA extracted, mRNA was used as a template for the synthesis of complementary DNA (cDNA) using Verso cDNA Synthesis Kit (Thermo Scientific, USA). The synthesized $\mathrm{cDNA}$ was stored at $-80^{\circ} \mathrm{C}$.

$\square$ This CDNA was used to study ESR expression by real-time quantitative PCR (RT-qPCR).

o Quantitative expression of ESRa gene by real-time PCR:

$\square$ Real-time PCR (Bio-Rad Connect) was used to measure the expression of ESR $\alpha$ gene in placental tissue of PPD cases and controls by determining delta $\mathrm{Ct}$ (cycle threshold).

$\square$ Primer sequences used for ESR $\alpha$ are as follows:

\begin{tabular}{lll}
\hline Genes & Forward & Reverse \\
\hline ESR $\alpha$ & 5'-AGCCAGTGCAATCAACA & 5'-GGTGCTCACTGGATTACCT \\
& CGA-3' & GAA-3' \\
GAPDH & 5'-CCAAGGTCATCCATG & 5'-TGTTGAAGTCAGAGG \\
& ACAACTTTGGT-3' & AGACCACCTG-3' \\
\hline
\end{tabular}

The reaction mixture of $20 \mu \mathrm{L}$ of a sample for a gene was made as follows:

\begin{tabular}{ll}
\hline Reagents & Volume $(\mu \mathrm{L})$ \\
\hline Master mix & 10 \\
Primer forward & 1 \\
Primer reverse & 1 \\
CDNA & 1 \\
Nuclease-free water (NFW) & 7 \\
\hline
\end{tabular}

The $P C R$ reaction condition that was followed for the amplification of $E S R \alpha$ gene is as follows:

\begin{tabular}{|c|c|c|c|c|}
\hline Gene & $\begin{array}{l}\text { Initial } \\
\text { denaturation }\end{array}$ & Denaturation & Annealing & Melt curve \\
\hline $\mathrm{ESR} \alpha$ & $95^{\circ} \mathrm{C}, 5$ minutes & $\begin{array}{l}95^{\circ} \mathrm{C} \\
30 \text { seconds } \\
\text { (39 cycles) }\end{array}$ & $\begin{array}{l}60^{\circ} \mathrm{C} \\
30 \text { seconds } \\
\text { (30 cycles) }\end{array}$ & $60-95^{\circ} \mathrm{C}$ \\
\hline
\end{tabular}

In the initial cycles of PCR, there is a little change in fluorescence signal (produced from double-stranded DNA). This defines the baseline for the amplification plot. An increase in fluorescence above the baseline indicates the detection of accumulated target. The parameter $\mathrm{Ct}$ (cycle threshold) is defined as the fractional cycle number at which the fluorescence passes the fixed threshold. Ct levels are inversely proportional to the amount of target nucleic acid in the sample, i.e., the lower the value of $\mathrm{Ct}$, the higher the amount of target nucleic acid in the sample. In this study, expression normalization was done using GAPDH gene to correct for sample-to-sample variations in RT-PCR efficiency and errors in sample quantification. $\Delta C t$ was evaluated, which is the difference of average Ct of target gene (ESR $\alpha$ gene) in case and their constitutive gene (GAPDH gene):

$\Delta \mathrm{Ct}=$ Average $\mathrm{Ct}$ _target - Average $\mathrm{Ct}$ _reference

Again, the difference of mean $\mathrm{Ct}$ values of controls and cases was determined, which is delta-delta $\mathrm{Ct}(\Delta \Delta \mathrm{Ct})$.

$$
\Delta \Delta \mathrm{Ct}=\Delta \mathrm{Ct} \_ \text {case }-\Delta \mathrm{Ct} \_ \text {control }
$$

After this, true fold change (FC) was represented to compare the expression of genes between cases and controls by the following formula:

$$
\mathrm{FC}=2^{-\Delta \Delta \mathrm{Ct}}
$$

\section{Data Compilation}

At the end of study, data were compiled and studied as follows:-

- Comparison of sociodemographic and clinical profile of cases and controls

- Quantification, analysis, and comparison of estrogen receptor alpha gene expression levels in placental tissue of cases and controls.

- Proportion of postpartum depression (PPD).

- Correlation between estrogen receptor alpha (ESR $\alpha)$ gene expression and risk factors.

\section{Statistical Analysis of Data}

Data were analyzed as follows:-

Microsoft Excel (version 2007) and statistical software SPSS for windows (version 17.0) were used for data presentation and statistical analysis. $p$ value $<0.05$ was considered as significant.

- Unpaired Student's t-test and Chi-square/Fisher's exact test were applied to compare all sociodemographic characteristics, clinical profile, and ESR gene expression in cases and controls according to data being quantitative and qualitative, respectively.

- Pearson coefficient of correlation was used to test the correlation between EPDS score and $\triangle C T$ of ESR gene expression.

- Spearman coefficient of correlation was used to find out correlation between gene expression of ESR $\alpha$ and risk factors.

\section{Outcome Measures}

Primary Outcome

- Measurement of fold change in ESR $\alpha$ gene expression in placental tissue of women having postpartum depression and in women who did not have depression after delivery.

\section{Secondary Outcome}

- Assessment of the proportion, risk factors, and demographic profile of women with postpartum depression.

- Correlation of the estrogen receptor alpha (ESR $\alpha)$ gene expression with risk factors.

\section{Results}

Out of 209 patients, 16 patients could not follow the study and three patients were found with EPDS scores 10, 12, and 13 but were not found to be depressed on psychiatric evaluation. All the study subjects were followed at 2 weeks and 6 weeks after delivery. EPDS score 9 was taken as cutoff point. Women with score $>9$ were taken as cases for PPD and were confirmed by psychiatrist. In our study, 17 women were found having PPD at 2 weeks and 13 patients developed PPD at 6 weeks (Fig. 1).

The proportion of PPD was 16\% (30 out of 190) at 6 weeks, taking EPDS score 9 as cutoff. The results were categorized into three parts:

\section{Sociodemographic, past, and personal characteristics (Table 1):}

The mean age of women in cases was 25.57 ( \pm 2.77 SD) years and in controls was $26.23( \pm 3.35 \mathrm{SD})$ years. Majority of the women belonged to the middle class, followed by lower class. Among PPD women, $53.4 \%$ belonged to lower class, whereas among 
Table 1: Sociodemographic, past, and personal profile of cases and controls $(n=60)$

\begin{tabular}{|c|c|c|c|c|}
\hline & $n=60$ & Case (30) & Control (30) & $p$ value \\
\hline \multicolumn{5}{|c|}{ Age distribution ( years) } \\
\hline $20-25$ & 28 & $14(46.7 \%)$ & $14(46.7 \%)$ & $1.000^{*}$ \\
\hline $26-30$ & 30 & $15(50 \%)$ & $15(50 \%)$ & \\
\hline $31-35$ & 1 & $1(3.3 \%)$ & $0(0 \%)$ & \\
\hline$>35$ & 1 & $0(0 \%)$ & $1(3.3 \%)$ & \\
\hline \multicolumn{5}{|l|}{ Religion } \\
\hline Hindu & 44 & $20(66.7 \%)$ & $24(80 \%)$ & 0.222 \\
\hline Muslim & 14 & $9(30 \%)$ & $5(16.7 \%)$ & \\
\hline Sikh & 2 & $1(3.3 \%)$ & $1(3.3 \%)$ & \\
\hline Christian & 0 & $0(0 \%)$ & $0(0 \%)$ & \\
\hline \multicolumn{5}{|l|}{ Socioeconomic status } \\
\hline Upper & 0 & $0(0 \%)$ & $0(0 \%)$ & $<0.001$ \\
\hline Upper middle & 8 & $4(13.3 \%)$ & $4(13.3 \%)$ & \\
\hline Lower middle & 30 & $7(23.3 \%)$ & $23(76.7 \%)$ & \\
\hline Upper lower & 19 & $16(53.4 \%)$ & $3(10 \%)$ & \\
\hline Lower & 3 & $3(10 \%)$ & $0(0 \%)$ & \\
\hline \multicolumn{5}{|l|}{ Type of family } \\
\hline Joint & 45 & $18(60 \%)$ & 27 (90\%) & $<0.001^{*}$ \\
\hline Nuclear & 15 & $12(40 \%)$ & $3(10 \%)$ & \\
\hline \multicolumn{5}{|l|}{ Marital status } \\
\hline Married & 58 & $28(93.4 \%)$ & $30(100 \%)$ & $0.492^{*}$ \\
\hline Separated & 2 & $2(6.6 \%)$ & $0(0 \%)$ & \\
\hline $\begin{array}{l}\text { Single/widow/ } \\
\text { partnered/divorced }\end{array}$ & 0 & $0(0 \%)$ & $0(0 \%)$ & \\
\hline \multicolumn{5}{|c|}{ Duration of marriage (years) } \\
\hline $0-5$ & 28 & $13(43.4 \%)$ & $15(50 \%)$ & $0.064^{*}$ \\
\hline $6-10$ & 23 & $9(30 \%)$ & $14(46.7 \%)$ & \\
\hline $11-15$ & 8 & $7(23.3 \%)$ & $1(3.3 \%)$ & \\
\hline$>15$ & 1 & $1(3.3 \%)$ & $0(0 \%)$ & \\
\hline \multicolumn{5}{|l|}{ Sleep } \\
\hline Normal & 56 & $26(86.6 \%)$ & $30(100 \%)$ & $0.112^{*}$ \\
\hline Disturbed & 4 & $4(13.3 \%)$ & $0(0 \%)$ & \\
\hline \multicolumn{5}{|l|}{ Addiction } \\
\hline Yes & 1 & $0(0 \%)$ & $1(3.3 \%)$ & $1.000^{*}$ \\
\hline No & 59 & $30(100 \%)$ & $29(96.7 \%)$ & \\
\hline \multicolumn{5}{|l|}{ Antenatal anxiety } \\
\hline Yes & 16 & $14(46.7 \%)$ & $2(6.6 \%)$ & $<0.001$ \\
\hline No & 46 & $16(53.3 \%)$ & $28(93.4 \%)$ & \\
\hline \multicolumn{5}{|l|}{ Depression } \\
\hline Yes & 1 & $1(3.3 \%)$ & $0(0 \%)$ & $1.000^{*}$ \\
\hline No & 59 & $29(96.7 \%)$ & $30(100 \%)$ & \\
\hline \multicolumn{5}{|l|}{ Medical illness } \\
\hline No medical illness & 54 & $26(86.7 \%)$ & $28(93.3 \%)$ & $0.704^{*}$ \\
\hline $\begin{array}{l}\text { Medical illness present } \\
\text { (hypertension/diabetes/ } \\
\text { epilepsy/anemia/ } \\
\text { tuberculosis/thyroid } \\
\text { disease }\end{array}$ & 6 & $4(13.3 \%)$ & $2(6.7 \%)$ & \\
\hline \multicolumn{5}{|l|}{ Drug history } \\
\hline Yes & 2 & $1(3.3 \%)$ & $1(3.3 \%)$ & $1.000^{*}$ \\
\hline No & 58 & $29(96.7 \%)$ & $29(96.7 \%)$ & \\
\hline
\end{tabular}

controls, $76.7 \%$ belonged to middle class. Statistically significant association was found between postpartum depression and lower socioeconomic status. PPD was more likely in women with lower socioeconomic status ( $p$ value $<0.001$ ).

Among PPD cases, $60 \%$ belonged to joint family vs $90 \%$ among controls. Statistically significant association ( $p$ value $<0.001$ ) was found between nuclear family and postpartum depression. This is suggestive of the fact that the joint family is a protective factor for PPD.

No statistical significance ( $p$ value 0.092 ) was found between gravidity and PPD, but significant association ( $p$ value $<0.001$ ) was found between PPD and previous female gender. So we can interpret that women having previous female child were more prone to PPD.

A total of $91.6 \%$ women had unplanned pregnancy among both the groups. Both the groups were comparable, and pregnancy planning was not statistically significant ( $p$ value 0.323 ) for PPD.

Majority of women wanted to continue the pregnancy, 20 from the case group and 28 from the control group. Only $41.66 \%$ had depression and among who did not want to continue 7 , but continued because of family pressure, failure of contraception and got to know about pregnancy very late, or because of some other reasons, all of them were found to be depressed in their postpartum period. Statistically significant association was found ( $p$ value 0.011 ) between postpartum depression and unwanted pregnancy (Fig. 2).

No significant association ( $p$ value 0.112 ) was found between PPD and sleep pattern or addiction among both the groups.

Significant association ( $p$ value $<0.001$ ) was found between PPD and antenatal anxiety. Depression was more likely in study participants having antenatal anxiety.

No significant association ( $p$ value 1.000) was found between PPD and past history of depression or ( $p$ value 0.704 ) any medical illness or medications.

No significant association ( $p$ value 0.502 ) was found between PPD and intrapartum complications. Majority of women had vaginal delivery in both the study groups, and no significant association ( $p$ value 0.731 ) was found between PPD and mode of delivery (Table 2).

Majority of women delivered a male child. No significant association ( $p$ value 0.795 ) was found between PPD and gender of the child or birth weight ( $p$ value 0.430 ). Among PPD cases, $3.3 \%$

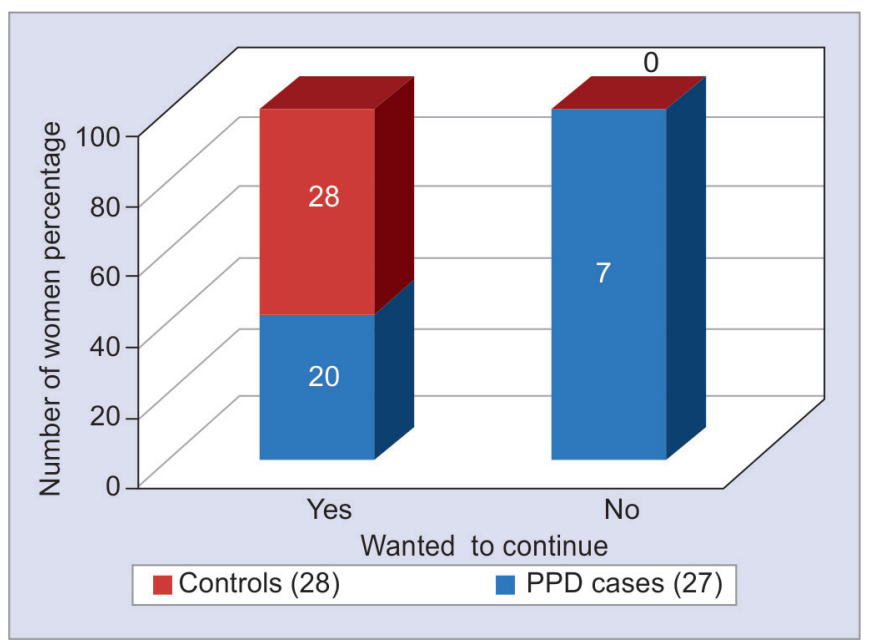

Fig. 2: Comparison of desire of pregnancy in cases and controls 
Placental Tissue Estrogen Receptor Alpha Gene Expression

Table 2: Intrapartum details of cases and controls

\begin{tabular}{|c|c|c|c|c|}
\hline & $n=60$ & Case (30) & Control (30) & $p$ value \\
\hline \multicolumn{5}{|l|}{ Intrapartum complication } \\
\hline No complication & 50 & $26(86.7 \%)$ & $24(80 \%)$ & $0.502^{*}$ \\
\hline $\begin{array}{l}\text { Complications } \\
\text { (nonprogress of labor/ } \\
\text { second-stage arrest/fetal } \\
\text { distress/abruption) }\end{array}$ & 10 & $4(13.3 \%)$ & $6(20 \%)$ & \\
\hline \multicolumn{5}{|l|}{ Mode of delivery } \\
\hline Vaginal & 50 & $26(86.6 \%)$ & $24(80 \%)$ & $0.731^{*}$ \\
\hline Cesarean & 9 & $4(13.3 \%$ & $5(16.6 \%)$ & \\
\hline $\begin{array}{l}\text { Instrumental (forceps/ } \\
\text { vacuum) }\end{array}$ & 1 & $0(0 \%)$ & $1(3.3 \%)$ & \\
\hline
\end{tabular}

Table 3: Neonatal outcome

\begin{tabular}{lrccc}
\hline & $n=60$ & Case (30) & Control (30) & $p$ value \\
\hline $\begin{array}{l}\text { Gender of the child } \\
\text { Male }\end{array}$ & 34 & $16(53.3 \%)$ & $18(60 \%)$ & $0.795^{*}$ \\
Female & 26 & $14(46.6 \%)$ & $12(40 \%)$ & \\
Baby birth weight (kg) & & & & \\
$\geq 2.5$ & 35 & $19(63.4 \%)$ & $16(53.4 \%)$ & $0.430^{*}$ \\
$<2.5$ & 24 & $10(33.3 \%)$ & $14(46.6 \%)$ & \\
$<1.5$ & 1 & $1(3.3 \%)$ & $0(0 \%)$ & \\
Baby status & & & & \\
Healthy & 48 & $21(70 \%)$ & $27(90 \%)$ & $0.035^{*}$ \\
Stillbirth & 1 & $1(3.3 \%)$ & $0(0 \%)$ & \\
IUD & 2 & $2(6.7 \%)$ & $0(0 \%)$ & \\
NICU admissions & 9 & $6(20 \%)$ & $3(10 \%)$ & \\
Home expiry & 0 & $0(0 \%)$ & $0(0 \%)$ & \\
\hline
\end{tabular}

*Fisher's exact test

had stillbirth, $6.6 \%$ intrauterine death (IUD), and $20 \%$ babies were shifted to neonatal ICU. Significant association ( $p$ value 0.035 ) was found between PPD and poor neonatal outcome (Table 3).

No statistical association was found between PPD cases and postpartum complications or prolonged hospital stay.

Majority of women in both PPD case and control groups had preference for male child, but no significant association ( $p$ value 0.071) was found between PPD and gender preference.

Significant association ( $p$ value $<0.001$ ) was found between PPD and family pressure for male child. Depression was more likely among women, having some pressure for male gender. Only $20 \%$ of PPD and $80 \%$ of controls had some decision-making authority. Significant association ( $p$ value $<0.001$ ) was found between PPD and decision-making power.

Depression was more likely in study participants having no decision-making power. None of the women in the case and control groups had the independent decision-making authority. Significant association ( $p$ value $<0.001$ ) was found between PPD and low selfesteem of the study groups. A total of $40 \%$ PPD women had no support from their spouse, and among control groups, all women were receiving adequate support from their partner. Significant association ( $p$ value $<0.001$ ) was found between PPD and partner support. Depression was more likely among women having no support from their partner. Significant association ( $p$ value $<0.001)$
Table 4: Various factors contributing postpartum depression

\begin{tabular}{|c|c|c|c|c|}
\hline & $n=60$ & Case (30) & Control (30) & pvalue \\
\hline \multicolumn{5}{|l|}{ Gender preference } \\
\hline Male & 43 & $24(80 \%)$ & $19(63.4 \%)$ & $0.071^{*}$ \\
\hline Female & 13 & $3(10 \%)$ & $10(33.3 \%)$ & \\
\hline No preference & 4 & $3(10 \%)$ & $1(3.3 \%)$ & \\
\hline \multicolumn{5}{|c|}{ Pressure for male child } \\
\hline Yes & 22 & $19(63.4 \%)$ & $3(10 \%)$ & $<0.001$ \\
\hline No & 38 & $11(36.6 \%)$ & $27(90 \%)$ & \\
\hline \multicolumn{5}{|c|}{ Independent decision-making power } \\
\hline Yes & 0 & 0 & 0 & $<0.001$ \\
\hline No & 30 & $24(80 \%)$ & $6(20 \%)$ & \\
\hline $\begin{array}{l}\text { Together with the } \\
\text { husband }\end{array}$ & 30 & $6(20 \%)$ & $24(80 \%)$ & \\
\hline \multicolumn{5}{|l|}{ Self-esteem } \\
\hline Low & 14 & $13(43.3 \%)$ & $1(3.3 \%)$ & $<0.001$ \\
\hline Positive & 46 & $17(56.7 \%)$ & $29(96.7 \%)$ & \\
\hline \multicolumn{5}{|l|}{ Partner support } \\
\hline Yes & 48 & $18(60 \%)$ & $30(100 \%)$ & $<0.001$ \\
\hline No & 12 & $12(40 \%)$ & $0(0 \%)$ & \\
\hline \multicolumn{5}{|l|}{ Family support } \\
\hline Yes & 37 & $11(36.6 \%)$ & $26(86.6 \%)$ & $<0.001$ \\
\hline No & 23 & $19(63.4 \%)$ & $4(13.4 \%)$ & \\
\hline \multicolumn{5}{|l|}{ Life stress } \\
\hline Yes & 19 & $16(53.3 \%)$ & $3(10 \%)$ & $<0.001$ \\
\hline No & 41 & $14(46.7 \%)$ & $27(90 \%)$ & \\
\hline \multicolumn{5}{|l|}{ Domestic violence } \\
\hline Yes & 10 & $8(26.6 \%)$ & $2(6.6 \%)$ & 0.038 \\
\hline No & 50 & $22(73.3 \%)$ & $28(93.3 \%)$ & \\
\hline \multicolumn{5}{|l|}{ Infant temperament } \\
\hline Irritable & 34 & $16(63.3 \%)$ & $18(60 \%)$ & $0.846^{*}$ \\
\hline Fussy & 10 & $4(13.3 \%)$ & $6(20 \%)$ & \\
\hline Difficult to console & 9 & $5(16.6 \%)$ & $4(13.3 \%)$ & \\
\hline \multicolumn{5}{|c|}{ Medical illness in baby } \\
\hline III & 6 & $5(16.6 \%)$ & $1(3.3 \%)$ & $0.089^{*}$ \\
\hline Healthy & 47 & $20(66.6 \%)$ & $27(90 \%)$ & \\
\hline \multicolumn{5}{|c|}{ History of maternity blues } \\
\hline Present & 19 & $14(46.6 \%)$ & $5(16.6 \%)$ & $0.009 *$ \\
\hline Absent & 41 & 16 (53.4\%) & 25 (83.4\%) & \\
\hline
\end{tabular}

*Fisher's exact test

was found between PPD and family support. Depression was more likely in women having no family support.

Among PPD cases, 53.3\% women had some life stress factors as compared to only $10 \%$ women in control group. Life stress factors included financial problems, marital problems, any illness or death in the family, and unemployment. Significant association ( $p$ value $<0.001$ ) was found between PPD and stress factors in life. Among PPD cases, $26.6 \%$ and control group $6.6 \%$ had history of domestic violence. Depression was more likely in study participants having history of domestic violence with them.

No significant association ( $p$ value 0.846 ) was found between PPD and infant temperament or medical illness in baby. However, $46.6 \%$ of PPD women had history of maternity blues as compared to only $16.6 \%$ in control group. Significant association ( $p$ value 0.009 ) was found between PPD and maternity blues, and women with history of maternity blues were more prone to depression (Table 4). 


\section{Comparison of proportion of estrogen receptor alpha gene expression among cases and controls} (Fig. 3, Table 5)

Real-time PCR (Bio-Rad Connect) was used to measure the expression of ESR $\alpha$ gene in placental tissue of PPD cases and controls by determining delta Ct (cycle threshold). In the initial cycles of PCR, there is a little change in fluorescence signal (produced from double-stranded DNA). This defines the baseline for the amplification plot. An increase in fluorescence above the baseline indicates the detection of accumulated target. The parameter $\mathrm{Ct}$ (cycle threshold) is defined as the fractional cycle number at which the fluorescence passes the fixed threshold. $\mathrm{Ct}$ levels are inversely proportional to the amount of target nucleic acid in the sample, i.e., the lower the value of $\mathrm{Ct}$, the higher the amount of target nucleic acid in the sample. In this study, expression normalization was done by GAPDH gene. $\Delta C$ t was evaluated, which is the difference of average Ct of target gene (ESR $\alpha$ gene) in case and their constitutive gene (GAPDH gene): $\Delta \mathrm{Ct}=$ Average Ct_target - Average Ct_reference

The lower the value of ESR $\alpha$ delta $\mathrm{Ct}$, the higher the expression of ESR gene.

Again, the difference of mean $\mathrm{Ct}$ values of controls and cases was determined, which is delta-delta $\mathrm{Ct}(\Delta \Delta \mathrm{Ct}) . \Delta \Delta \mathrm{Ct}=\Delta \mathrm{Ct}$ case $-\Delta$ Ct_control

After this, true fold change (FC) was represented to compare the expression of genes between cases and controls by the following formula:

$\mathrm{FC}=2^{-\Delta \Delta \mathrm{Ct}}$

After performing the real-time PCR for ESR $\alpha$ gene and normalizing it with GAPDH, which is internal control, ESR $\alpha$ gene was found to be significantly downregulated by 1.33 times among cases as compared to controls.

Further independent $t$-test analysis was found to be significant with $p$ value 0.032 .

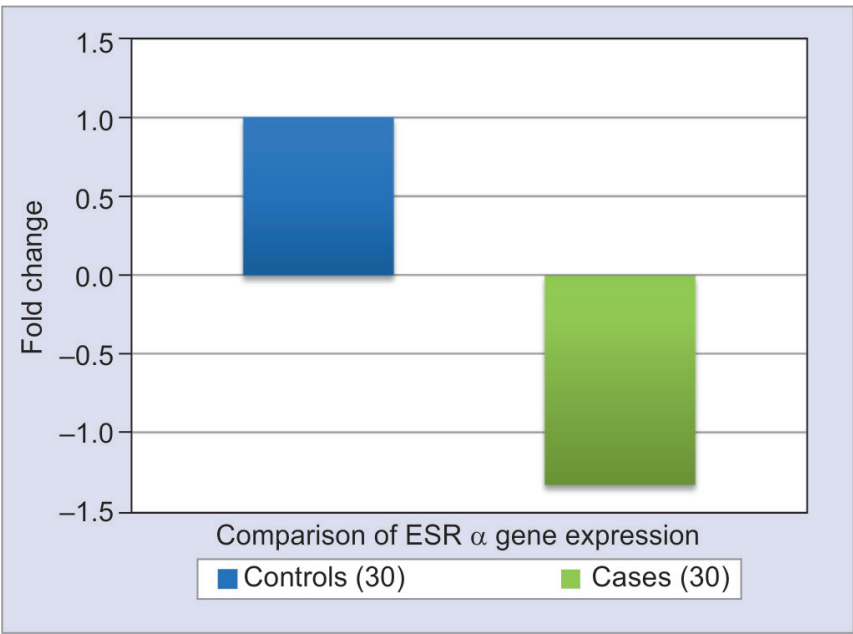

Fig. 3: Comparison of ESR $\alpha$ gene expression in controls and cases

Table 5: Comparison of ESR $\alpha$ gene expression in controls and cases

\begin{tabular}{llllll}
\hline & $n$ & Mean (delta $C t)$ & Std dev & Std error mean & $p$ value \\
\hline Case & 30 & 3.33 & 0.697 & 0.127 & 0.032 \\
Control & 30 & 2.91 & 0.759 & 0.138 & \\
\hline
\end{tabular}

The placental ESR $\alpha$ delta Ct value in cases was significantly higher with respect to controls. So, we can interpret that estrogen receptor gene expression downregulation is significantly associated with postpartum depression.

Thus, we can infer that women developing PPD after delivery have significantly lower expression of ESR $\alpha$ gene in their placenta at the time of delivery, which is 1.33 times less as compared to women who remain healthy.

\section{Comparison of proportion of estrogen receptor alpha gene expression with each risk factor} (Tables 6 and 7)

Negative correlation was found between socioeconomic status and ESR gene expression, but it was not statistically significant ( $p$ value 0.889 ).

Weak correlation was found between marital status and ESR gene expression, but it was not ( $p$ value 0.808 ) statistically significant.

Negative correlation was found between self-esteem and ESR gene expression, but it was not found to be statistically significant ( $p$ value 0.134 ). Negative correlation was found between antenatal anxiety and ESR gene expression, and it was statistically significant ( $p$ value 0.002 )

Correlation was found between planned pregnancy and ESR gene expression, but it was not found to be statistically significant ( $p$ value 0.457 ).

Weak correlation was found between depression history and ESR gene expression, but it was not found to be statistically significant ( $p$ value 0.120 ).

Weak correlation, not statistically significant, was found between ESR gene expression and partner support ( $p$ value 0.350 ) and family support and ESR gene expression ( $p$ value 0.129 ).

Weak correlation was found between marital satisfaction and ESR gene expression, and it was statistically significant ( $p$ value 0.010).

Negative correlation was found between life stress and ESR gene expression, but it was not found to be statistically significant ( $p$ value 0.272 ).

\section{Discussion}

There are very few studies on postpartum depression, and among them, studies for gene expression and postpartum depression correlation are very much less. This study provides information on the proportion of post partum depression, various risk factors associated with postpartum depression and placental estrogen receptor $\alpha$ gene expression, and the association of placental estrogen receptor $\alpha$ gene expression with postpartum depression.

\section{Proportion of Postpartum Depression}

The worldwide prevalence of PPD ranges from $1-73.7 \%$ using various tools and rating scales. ${ }^{10}$ The variability of prevalence of PPD can be explained by the fact that different studies had employed different scales and at different time in the postpartum period. It may also be influenced by the cross-cultural differences in different regions, differences in perception of mental health, and stigma associated with it.

The proportion of postpartum depression in our study was found to be $8.9 \%$ at 2 weeks and $16 \%$ at 6 weeks as measured by EPDS taking score 9 as a cutoff for PPD. The prevalence of postpartum depression has been reported to range from $3.2-48.5 \%$ in different studies conducted in India. ${ }^{11-24}$ 
Placental Tissue Estrogen Receptor Alpha Gene Expression

Table 6: Correlation between various risk factors and estrogen receptor alpha gene expression

\begin{tabular}{|c|c|c|c|c|c|}
\hline Socioeconomic status & & & DeltaCt & SES & $p$ value \\
\hline \multirow[t]{4}{*}{ Spearman's rho } & Delta Ct & Correlation coefficient & 1.000 & -0.027 & 0.889 \\
\hline & & Sig. (two-tailed) & - & 0.889 & \\
\hline & SES & Correlation coefficient & -0.027 & 1.000 & \\
\hline & & Sig. (two-tailed) & 0.889 & - & \\
\hline Marital status & & & DeltaCt & Marital status & $p$ value \\
\hline \multirow[t]{2}{*}{ Spearman's rho } & Delta Ct & Correlation coefficient & 1.000 & 0.046 & 0.808 \\
\hline & Marital status & Correlation coefficient & 0.046 & 1.000 & \\
\hline Self-esteem & & & DeltaCt & Self-esteem & $p$ value \\
\hline \multirow[t]{2}{*}{ Spearman's rho } & Delta Ct & Correlation coefficient & 1.000 & -0.280 & 0.134 \\
\hline & Self-esteem & Correlation coefficient & -0.280 & 1.000 & \\
\hline Antenatal anxiety & & & DeltaCt & Antenatal anxiety & $p$ value \\
\hline \multirow[t]{2}{*}{ Spearman's rho } & Delta Ct & Correlation coefficient & 1.000 & -0.548 & 0.002 \\
\hline & Antenatal anxiety & Correlation coefficient & -0.548 & 1.000 & \\
\hline Planned pregnancy & & & DeltaCt & Planned pregnancy & $p$ value \\
\hline \multirow[t]{2}{*}{ Spearman's rho } & Delta Ct & Correlation coefficient & 1.000 & -0.141 & 0.457 \\
\hline & Planned pregnancy & Correlation coefficient & -0.141 & 1.000 & \\
\hline History of depression & & & DeltaCt & Depression history & $p$ value \\
\hline \multirow[t]{2}{*}{ Spearman's rho } & Delta Ct & Correlation coefficient & 1.000 & 0.290 & 0.120 \\
\hline & Depression history & Correlation coefficient & 0.290 & 1.000 & \\
\hline Partner support & & & Delta Ct & Partner support & $p$ value \\
\hline \multirow[t]{2}{*}{ Spearman's rho } & Delta Ct & Correlation coefficient & 1.000 & 0.177 & 0.350 \\
\hline & Partner support & Correlation coefficient & 0.177 & 1.000 & \\
\hline Family support & & & Delta Ct & Family support & $p$ value \\
\hline \multirow[t]{2}{*}{ Spearman's rho } & Delta Ct & Correlation coefficient & 1.000 & 0.284 & 0.129 \\
\hline & Family support & Correlation coefficient & 0.284 & 1.000 & \\
\hline Marital satisfaction & & & Delta Ct & Marital satisfaction & $p$ value \\
\hline \multirow[t]{2}{*}{ Spearman's rho } & Delta Ct & Correlation coefficient & 1.000 & 0.462 & 0.010 \\
\hline & Marital satisfaction & Correlation coefficient & 0.462 & 1.000 & \\
\hline Life stress & & & Delta Ct & Life stress & $p$ value \\
\hline \multirow[t]{2}{*}{ Spearman's rho } & Delta Ct & Correlation coefficient & 1.000 & -0.207 & 0.272 \\
\hline & Life stress & Correlation coefficient & -0.207 & 1.000 & \\
\hline
\end{tabular}

Table 7: Correlation of placental estrogen receptor alpha gene expression with each risk group (summarized)

\begin{tabular}{lcc}
\hline & $\begin{array}{c}\text { Spearman's rho correlation } \\
\text { coefficient }\end{array}$ & p value \\
\hline Socioeconomic status & -0.027 & 0.889 \\
Marital status & 0.046 & 0.808 \\
Self-esteem & -0.280 & 0.134 \\
Antenatal anxiety & -0.548 & 0.002 \\
Planned pregnancy & -0.141 & 0.457 \\
History of depression & 0.290 & 0.120 \\
Partner support & 0.177 & 0.350 \\
Family support & 0.284 & 0.129 \\
Marital satisfaction & 0.462 & 0.010 \\
Life stress & -0.207 & 0.272 \\
\hline bold figures show negative correlation and were statistically significant
\end{tabular}

The low prevalence of postpartum depression found by Gokhale et al. ${ }^{9}$ may be due to the fact that they had used a high cutoff of 12 for EPDS. ${ }^{19}$ They screened around 200 patients on 1st postnatal day and followed them on 6th postnatal day and 6th postnatal week. Taking 12 as the cutoff for PPD, the prevalence of PPD was found to $11 \%$ on 1 st day postpartum, $7.4 \%$ at 6 th day postpartum, and $3.2 \%$ at 6 weeks postpartum.

The prevalence of postpartum depression in Delhi was 15.8\% (out of 202 women, 32 were diagnosed with depression) as reported by Gupta et al., ${ }^{4}$ which is almost near to the findings of our study even though both the studies differed in the scale used as screening tool. Gupta et al. ${ }^{4}$ had conducted the study in a tertiary hospital of Delhi on women who had attended postnatal clinic at 6 weeks postpartum using PRIME-MD TODAY, whereas in our study, we used EPDS as the screening tool.

\section{Risk Factors for Postpartum Depression}

Age

In our study, age was not found to be a risk factor for the development of postpartum depression and similar results were reported by Green et al. and some other researchers. ${ }^{21}$

\section{Socioeconomic Status}

When a new baby is born, there is a decrease in disposable income due to the added financial responsibilities that come along with the addition of a new member. This means lesser finance to spend on their needs and leisure activities. ${ }^{17,18}$ We found a significant association 
( $p$ value $<0.001$ ) of postpartum depression and poverty status of study participants. Majority of the cases developing PPD (53.4\%) belonged to lower class, whereas among controls, majority $(76.7 \%)$ belonged to middle class. Comparable findings have been reported by other researchers also. Similarly, Silva et al. ${ }^{16}$ found a positive association between lower socioeconomic status and postpartum depression. He studied a cohort of 1,109 women in their prenatal and postnatal periods. He concluded that lower socioeconomic status was significantly associated with PPD ( $p=0.020$, RR $1.76,95 \% \mathrm{Cl})$.

\section{Type of Family}

Statistically significant association ( $p$ value $<0.001$ ) was found between nuclear family and postpartum depression. Mothers in joint families get more support during physically and mentally stressful postpartum period. Similar findings of protective effect of joint family have been reported by other researchers. ${ }^{11-16}$

\section{Marital Status}

Marital status was not found to be significant, reason being less number of single mothers participated in our study. Contrary to this, Ghosh et al. ${ }^{8}$ found significant association between single mother and postpartum depression (widow 96\%, unmarried 100\%, separated $100 \%$ showing higher preponderance).

\section{Unplanned Pregnancy and Unwanted Pregnancy}

We did not find any association between unplanned pregnancy and postpartum depression. Similar results were reported by Mathisen et al. and Al Hinai et al..$^{14,15}$ However, Klainin et al. ${ }^{13}$ found a significant association between postpartum depression and unplanned pregnancy (OR 11.94, 95\% Cl 1.60-6.85, $p$ value 0.001 ) and also an association between unwanted pregnancy and PPD.

\section{Birth Weight and Neonatal Outcome}

Low birth weight babies are more prone to complications as compared to normal birth weight babies. Savarimuthu et al. ${ }^{7}$ reported that low birth weight of the baby may increase the risk of depression as they are more likely to be hospitalized because of some medical problems. We could not find any association between postpartum depression and birth weight of the child. It may be because most of the women in our study delivered a baby with birth weight $>2.5 \mathrm{~kg}$, and even if the birth weight was low in some participants, they did not suffer from any condition, which necessitated their admission to hospital or requiring ICU care. Comparable findings have been observed by Mahmud et al. ${ }^{12}$ who found no association between low birth weight of the child and postpartum depression).

But poor neonatal outcome (neonatal ICU admission, stillbirth, intrauterine fetal demise) was found significantly associated with PPD. Similar findings were observed by Ghosh et al. ${ }^{8}$

\section{Previous Medical IIIness and Past History of Depression}

We found no association between postpartum depression and any previous history of medical illness, and Mahmud et al. ${ }^{10}$ also had similar results. On the contrary, some researchers have speculated that past history of depression increases the possibility of development of postpartum depression. ${ }^{24}$ Gupta et al. ${ }^{4}$ also found the similar results (OR $33.4,95 \% \mathrm{Cl} 7.79-164.78$, $p$ value $<0.01$ ).

Gender of Previous Live Issue, Self-preference for Gender, and Family Pressure to have Male Child

Indian society is a male-dominated society, which leads to depression as found in our study, and it has been reported by many authors also.
Gupta et al. ${ }^{4}$ also reported higher incidence of PPD in women having previous girl child (OR 3.63, 95\% Cl 1.51-8.71, $p$ value $<0.001$ ) and pressure for male child (OR $2.64,95 \% \mathrm{Cl} 1.1-6.28, p$ value 0.02 ). Some researchers did not find any association between gender of the child and postpartum depression. ${ }^{24}$

\section{Support of Husband and Family}

Postpartum period is a special period in the reproductive life of women as they go through a lot of changes-physically, mentally, and socially. Women may find it difficult to adjust to the growing demands and added responsibilities of childbirth. To help her cope in these situations, she looks for support from her husband, family, and friends, which can be a predictor of postpartum depression. In our research, we found a significant inverse association between postpartum depression and support of husband and family members $(p<0.05)$. Similar findings have been corroborated by Gausia et al. ${ }^{24}$

\section{Marital Dissatisfaction}

As described above, support of husband and family members is very important factor to cope up with the postpartum adjustments and childcare stress. Marital dissatisfaction becomes an additional factor to postpartum stress. In our research, we found a significant association between postpartum depression and marital dissatisfaction. Similar findings have been observed by Savarimuthu et al. ${ }^{7}$

\section{Antenatal Anxiety and Life Stress}

Antenatal anxiety was found to be significantly associated with PPD. Similar to our study, Savarimuthu et al. ${ }^{7}$ also found the association between PPD and antenatal anxiety.

As the women are already under stress and burden of childcare, any adverse event might increase the responsibilities of a woman toward her family, which might cause psychological stress leading to postpartum depression. Silva et al. ${ }^{16}$ found that stressful life event is an important risk factor for the development of postpartum depression though not statistically significant.

\section{Self-esteem}

In our study, low self-esteem was significantly associated with PPD ( $p$ value $<0.001$ ). Similar findings were observed by Gokhle et al. ${ }^{9}$ ( $p$ value 0.02 ) and Klainin et al. ${ }^{13}$

\section{Independent Decision-making Power}

In our study, no women had independent decision power. Women could take decision with their husband, or they were not even allowed to participate. We found a significant association between no decision-making power and PPD. Klainin et al. ${ }^{13}$ found the similar results.

\section{Domestic Violence}

History of physical abuse and domestic violence was found to be a significant risk factor for PPD in our study. Similar findings were observed by Ghosh et al. ${ }^{8}$ ( $p$ value $\left.<0.05\right)$ and Savarimuthu et al. ${ }^{7}$ ( $p$ value 0.02 )

\section{Infant Temperament}

Difficult infant temperaments were not found significant in our study. Contrary to this, Klainin et al. ${ }^{13}$ found it significant for developing PPD. Maybe, we need a large sample size to reach any conclusion for this. 


\section{Maternity Blues}

History of maternity blues was found a significant risk factor for PPD. Similar findings were observed by Klainin et al.

\section{Placental Estrogen Receptor Alpha Gene Expression and Postpartum Depression}

There is no previous study associating placental estrogen receptor gene expression and postpartum depression. However, numerous studies are available, which suggest that fall in the estrogen levels in blood after delivery is significantly associated with postpartum depression, which we have already discussed in review. There was a study conducted by Kugaya et al. in $2003,{ }^{22}$ which concluded that 5-HT 2 A receptor binding was significantly increased after estrogen replacement therapy in the right prefrontal cortex (right precentral gyrus [Brodmann's area 9], inferior frontal gyrus [Brodmann's area 47], medial frontal gyrus [Brodmann's area 6,10], and the anterior cingulate cortex [Brodmann's area 32]).

Thus, we can say that estrogen has a role in PPD through serotonin signaling. Estrogen is involved in the regulation of serotonin receptor number and function also..$^{1-6}$ That is why, fluctuating estrogen levels across the women's reproductive life have been associated with depressed mood.

Osterlund et al. in $1999^{23}$ conducted a study in rats and observed a link between estrogen and serotonin 5-HT in depression. The mRNA levels of the estrogen receptor ER $\alpha$ and $\beta$ subtypes and the $5-\mathrm{HT} 1 \mathrm{~A}$ and $5-\mathrm{HT} 2 \mathrm{~A}$ receptors were analyzed in limbic areas of ovariectomized rats treated with $17 \mathrm{~b}$-estradiol. In many areas, estradiol was found to regulate the 5-HT receptor mRNA expression.

Ahokas et al. in $2001^{25}$ established the association between estradiol and postpartum depression and found that postpartum depression symptoms were associated with estradiol deficiency and symptoms reduced on treatment with 17 beta-estradiol. Estradiol acts through ESR receptors; thus, ESR receptors are involved in the pathway of depression.

Segman et al. ${ }^{19}$ conducted a case-control study by sampling blood from mothers shortly after delivery and compared it with peripheral blood mononuclear cell (PBMC) gene expression profiles between postpartum depression women and normal postpartum women. A differential gene expression signature was observed in postpartum depression women. The differentially expressed transcripts showed a high number (29 out of 73) of transcripts linked to estrogen signaling.

Mehta et al. ${ }^{20}$ also used peripheral blood gene expression profiles in a high-risk, longitudinal cohort. In the first and third pregnancy trimesters and early postpartum of 201 samples, gene expression was measured on Illumina Human HT12 v4 microarrays and plasma estradiol and estriol were measured. One hundred sixteen transcripts were differentially expressed between the PPD and euthymic women during the third trimester that allowed the prediction of PPD with an accuracy of $88 \%$. Within these transcripts, significant enrichment of transcripts implicated that women with PPD displayed an increased sensitivity to estrogen signaling, confirming the previously proposed hypothesis of increased sex steroid sensitivity as a susceptibility factor for PPD. These results suggest that PPD can be robustly predicted in currently euthymic women as early as the third trimester and these findings have implications for predictive testing of high-risk women and prevention and treatment for PPD.
There was a pilot study conducted in 2013 in University of California by El-lbiary et al. ${ }^{21}$ to assess the influence of genetic and environmental risk factors upon PPD. They recruited the patients having EPDS score $>14$ and $<7$ for cases and controls. At follow-up, venous blood samples were withdrawn and gene analysis was done. In the study, they selected 12 genes for analysis, including those involved with steroid hormone function (NR3C1, FKBP5, ESR1, ESR2, PGR, AR, AKR1C2), neurotransmitter function (SLC6A4, MAOA, COMT, HTR2A), and neurotrophin function (BDNF). As expected, strongest association was found between serotonin $2 A$ receptor (HTR2A) variants and PPD. They also found some association between estrogen receptor ESR1 variants (two variants rs 11155820 and 2273206 were studied) and PPD.

So we assumed that after delivery as estrogen levels fall (which is already proven), there will be less mRNA production and less translation to protein, which will lead to less expression of ESR receptors. And, this is proven in our study as ESR $\alpha$ gene in placental tissue was found to be significantly downregulated by 1.33 times among cases as compared to controls.

\section{Strength of Our Study}

The present study has the following strengths:

- This is the first study (to the best of our knowledge) that has been done on placental estrogen receptor gene expression and its association with postpartum depression.

- It is matched case-control study, and sample size is good enough to carry out a statistically significant molecular study.

- It was a follow-up study, and women were followed at 2 weeks and 6 weeks after delivery, so that no case was left undiagnosed

- The risk factors for postpartum depression have been identified. EPDS questionnaire was used, which is one of the most widely used tools for screening of postpartum depression. Participants, who were found to have PPD on screening, were confirmed from psychiatrist.

- This is the first Indian study that can fruitfully predict postpartum depression and thus provides scope for targeted approach.

\section{Limitations of Our Study}

Though validated screening tools were applied for data collection, there is always a chance of not getting the accurate data as the results found are based on women's perceptions. Small sample size for prevalence estimation. A larger sample size would be statistically better for more reliable interpretation of results.

\section{Conclusion}

Etiology of postpartum depression is still an unsolved mystery, and the molecular mechanism behind its onset is still to be unveiled. Women developing PPD after delivery have significantly lower expression of $\mathrm{ESR} \alpha$ gene in their placenta at the time of delivery, which is 1.33 times less as compared to women who remain healthy. The mean ESR $\alpha$ delta Ct value in PPD cases $(3.33 \pm 0.697 \mathrm{SD})$ was significantly higher than the controls $(2.91 \pm 0.759 \mathrm{SD})$, with $p$ value 0.032 . Thus, the downregulation of placental ESR $\alpha$ gene expression at delivery plays a crucial role in PPD. Women destined to develop postpartum depression can be identified by screening their placenta so that appropriate psychiatric support can be targeted to them. Thus, their interpersonal, motherchild bonding and marital harmony are maintained. However, further studies are needed to disclose placental ESR $\alpha$ signaling, which can 
be utilized in devising ESR $\alpha$ receptor agonists acting preferably on cytotrophoblast $(\mathrm{CT})$ receptors to prevent PPD.

\section{Recommendations}

- We recommend further such studies on a larger population to prove the molecular mechanism.

- To reduce the maternal morbidity, search for better targeted interventions at the molecular level is necessary and constant endeavor is needed in this regard until mechanism and triggers of PPD are fully understood.

- We recommend further studies on a large sample size at earlier gestational age for better understanding of placental ESR expression.

- Thus, future research can look into the role of safer, better, effective, and alternative placental ESR $\alpha$ agonists for the prevention of PPD.

\section{References}

1. ICD-10 Version:2010. Available at: http://apps.who.int/classifications/ icd10/browse/2010/en\#/F53.0 [Accessed on April 17, 2017].

2. Chen PJ. Postpartum depression from pregnancy guide. Hospital of the University of Pennsyvania. Available at: https://en.wikipedia.org/ wiki/Postpartum_depression [Accessed on April 2, 2017].

3. Canadian Mental Health Association. Postpartum depression. Available at: http://www.cmha.ca/mental_health/postpartumdepression [Accessed on April 10, 2017].

4. Gupta S, Kishore J, Mala YM, et al. Postpartum depression in north Indian women: prevalence and risk factors. J Obstet Gynaecol India 2013;63(4):223-229. DOI: 10.1007/s13224-013-0399-x.

5. Lokuge S, Frey BN, Foster JA, et al. Depression in women: windows of vulnerability and new insights into the link between estrogen and serotonin. J Clin Psychiatry 2011;72(11):e1563-e1569. DOI: 10.4088/ JCP.11com07089.

6. World Health Organization. Maternal mental health and child health and development. Literature review of risk factors and intervention of postpartum depression. Department of Mental Health and Substance Abuse. Geneva 2008. Available at: www.who.int/mental_health/ prevention/suicide/mmh\%26chd_chapter_1.pdf [Accessed on October 12, 2015].

7. Savarimuthu RJ, Ezhilarasu P, Charles $\mathrm{H}$, et al. Post-partum depression in the community: a qualitative study from rural South India. Int J Soc Psychiatry 2010;56(1):94-102. DOI: 10.1177/0020764008097756.

8. Ghosh A, Goswami S. Evaluation of post partum depression in a tertiary hospital. J Obstet Gynaecol India 2011;61(5):528-530. DOI: 10.1007/s13224-011-0077-9.

9. Gokhale AV, Vaja A. Screening for postpartum depression. Gujarat Med J 2013;68(2):46-51. DOI: 10.7860/JCDR/2018/28153.11844.

10. Dubey C, Gupta N, Bhasin S, et al. Prevalence and associated risk factors for postpartum depression in women attending a tertiary hospital, Delhi, India. Int J Soc Psychiatry 2012;58(6):577-580. DOI: 10.1177/0020764011415210.
11. Patel HL, Ganjiwale JD, Nimbalkar AS, et al. Characteristics of Postpartum Depression in Anand District, Gujarat, India. J Trop Pediatr 2015;61(5):364-369. DOI: 10.1093/tropej/fmv046.

12. Mohammad KI, Gamble J, Creedy DK. Prevalence and factors associated with the development of antenatal and postnatal depression among Jordanian women. Midwifery 2011;27(6):e238e245. DOI: 10.1016/j.midw.2010.10.008.

13. Klainin P, Arthur DG. Postpartum depression in Asian cultures: a literature review. Int J Nurs Stud 2009;46(10):1355-1373. DOI: 10.1016/j. ijnurstu.2009.02.012.

14. Al Hinai $\mathrm{Fl}, \mathrm{Al}$ Hinai SS. Prospective study on prevalence and risk factors of postpartum depression in Al-dakhliya governorate in oman. Oman Med J 2014;29(3):198-202.

15. Mathisen SE, Glavin K, Lien L, et al. Prevalence and risk factors for postpartum depressive symptoms in Argentina: a cross-sectional study. Int J Womens Health 2013;5:787-793. DOI: 10.2147/IJWH. S51436.

16. Silva R, Jansen $K$, Souza $L$, et al. Sociodemographic risk factors of perinatal depression: a cohort study in the public health care system. Rev Bras Psiquiatr 2012;34(2):143-148. DOI: 10.1590/s151644462012000200005.

17. Kirkan TS, Aydin N, Yazici E, et al. The depression in women in pregnancy and postpartum period: a follow-up study. Int J Soc Psychiatry 2015;61(4):343-349. DOI: 10.1177/0020764014543713.

18. Durson SM, Blackburn JR, Kutcher SP. An exploratory approach to the serotonergic hypothesis of depression: Bridging the synaptic gap. Med Hypotheses 2001;56(2):235-243. DOI: 10.1054/ mehy.2000.1187.

19. Segman RH, Goltser-Dubner T, Weiner I, et al. Blood mononuclear cell gene expression signature of postpartum depression. Mol Psychiatry 2010;15(1):93-100. DOI: 10.1038/mp.2009.65.

20. Mehta D, Newport DJ, Frishman G, et al. Early predictive biomarkers for postpartum depression point to a role for estrogen receptor signaling. Psychol Med 2014;44(11):2309-2322. DOI: 10.1017/ S0033291713003231.

21. El-Ibiary SY, Hamilton SP, Abel R, et al. A pilot study evaluating genetic and environmental factors for postpartum depression. Innov Clin Neurosci 2013;10(9-10):15-22. PMCID: PMC3849876.

22. Akira Kugaya, C Neill Epperson, Sami Zoghbi, et al. Increase in prefrontal cortex serotonin 2 A receptors following estrogen treatment in postmenopausal women. Am J Psychiatry 2003;160(8):1522-1524.

23. Osterlund MK, Overstreet $\mathrm{DH}$, Hurd YL. The flinders sensitive line rats, a genetic model of depression, show abnormal serotonin receptor mRNA expression in the brain that is reversed by 17beta-estradiol. Brain research Mol Brain Res 1999;74(1-2):158-166. DOI: 10.1016/ s0169-328x(99)00274-0.

24. Gausia K, Fisher C, Ali M, et al. Magnitude and contributory factors of postnatal depression: a community-based cohort study from a rural subdistrict of Bangladesh. Psychol Med 2009;39(6):999-1007. DOI: $10.1017 /$ S0033291708004455.

25. Ahokas A, Kaukoranta J, Wahlbeck K, et al. Estrogen deficiency in severe postpartum depression: successful treatment with sublingual physiologic 17beta-estradiol: a preliminary study. J Clin Psychiatry 2001;62(5):332-336. 